DAPSA/CDAPSA

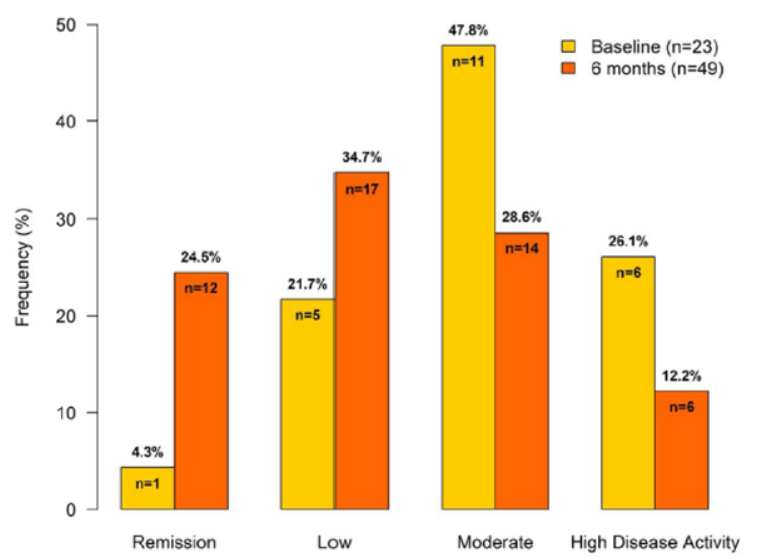

Figure 1. Classification of disease activity according to DAPSA at the indicated timepoints. Percentages in each category were calculated based on the number of patients with available data at each timepoint. DAPSA, Disease Activity in Psoriatic Arthritis.

Conclusion: Forty-one (75.9\%) patients with PsA naïve to biological therapies were treated with apremilast during $\geq 6$ months. After treatment, the number of swelling joints, and dactylitis and enthesitis decreased and changes in disease activity according to DAPSA and PGA pointed to a favorable disease evolution. Apremilast treatment provides a clinical benefit to patients with PsA treated in clinical practice.

REFERENCES:

[1] Gossec L, Smolen JS, Ramiro S, et al. European League Against Rheumatism (EULAR) recommendations for the management of psoriatic arthritis with pharmacological therapies: 2015 update. Ann Rheum Dis. 2016 Feb 10;75(3):499 LP-510

[2] Torres T and Puig L. Apremilast: A novel oral treatment for psoriasis and psoriatic arthritis. Am J clin Dermatol. 2018 Feb;19(1):23-32

[3] Coates LC, Kavanaugh A, Mease PJ et al. Group for Research and Assessment of Psoriasis and Psoriatic Arthritis 2015. Treatment Recommendations for Psoriatic Arthritis. Arthritis Rheumatol. 2016;68(5):1060- 71.

Disclosure of Interests: Jordi Gratacos-Masmitja Speakers bureau: MSD, Pfizer, AbbVie, Janssen Cilag, Novartis, Celgene y Lilly., Consultant of: MSD, Pfizer, AbbVie, Janssen Cilag, Novartis, Celgene y Lilly., José Luis Álvarez Vega Speakers bureau: Abbvie, Amgen, MSD, Lilly, Roche, Esteve, UCB, Menarini, Pfizer, GSK, BMS, Janssen, Novartis, Gebro., Consultant of: Abbvie, Amgen, MSD, Lilly, Roche, Esteve, UCB, Menarini, Pfizer, GSK, BMS, Janssen, Novartis, Gebro., Grant/research support from: Abbvie, Amgen, MSD, Lilly, Roche, Esteve, UCB, Menarini, Pfizer, GSK, BMS, Janssen, Novartis, Gebro., Emma Beltrán Speakers bureau: Abbvie, Bristol, Celgene, Janssen, Lilly, MSD, Novartis, Pfizer, Roche and UCB, Consultant of: Abbvie, Bristol, Celgene, Janssen, Lilly, MSD, Novartis, Pfizer, Roche and UCB, ANA URRUTICOECHEA-ARANA: None declared., C. Fito-Manteca: None declared., Francisco Maceiras: None declared., Joaquin Maria Belzunegui Otano Speakers bureau: Lilly, Amgen, Novartis, Abbvie, Janssen., J. Fernández-Melón Speakers bureau: Amgen SL, Eugenio Chamizo Carmona: None declared., Abad Hernández Speakers bureau: MSD, Abbvie, Pfizer, Kern, Novartis, Biogen, Sandoz, Amgen, Sanofi, Lilly, Roche and Janssen-Cilag, Consultant of: MSD, Abbvie, Pfizer, Kern, Novartis, Biogen, Sandoz, Amgen, Sanofi, Lilly, Roche and Janssen-Cilag, Grant/research support from: MSD, Abbvie, Pfizer, Kern, Novartis, Biogen, Sandoz, Amgen, Sanofi, Lilly, Roche and Janssen-Cilag, Inmaculada Ros Consultant of: Amgen, Grant/research support from: MSD, Roche, Novartis, lilly, Pfizer, Amgen, Eva Pascual Shareholder of: Amgen, Employee of: Amgen, Juan Carlos Torre Speakers bureau: Amgen, Lilly, Novartis, Janssen, Pfizer, Consultant of: Amgen, Lilly, Novartis, Janssen, Pfizer, Grant/research support from: Amgen, Lilly, Novartis, Janssen, Pfizer. DOI: 10.1136/annrheumdis-2021-eular.1621

\section{AB0543 2 CHARACTERISTICS AND TREATMENT CHANGES IN PATIENTS WITH PSORIATIC ARTHRITIS SEEN IN A COMBINED DERMATOLOGY-RHEUMATOLOGY CLINIC}

K. Klavdianou ${ }^{1}$, M. Stavropoulou ${ }^{2}$, P. Panagakis ${ }^{3}$, M. Papoutsaki ${ }^{4}$,

A. Panagiotopoulos ${ }^{1}$, C. Koutsianas ${ }^{1}$, A. Stratigos ${ }^{4}$, D. Rigopoulos ${ }^{4}$,

D. Vassilopoulos ${ }^{1} .{ }^{1}$ Hippokration General Hospital, 2nd Department of

Medicine and Laboratory, Clinical Immunology - Rheumatology Unit, National and Kapodistrian University of Athens, School of Medicine, Athens, Greece;

${ }^{2}$ National and Kapodistrian University of Athens, MSc Program "Rheumatology
- Musculoskeletal Health", Athens, Greece; ${ }^{3}$ A. Syggros Hospital, Department of Dermatology-Venereology, Athens, Greece; ${ }^{4}$ A. Syggros Hospital, 1 st Department of Dermatology and Venereology, National and Kapodistrian University of Athens, Athens, Greece

Background: Data on patients with Psoriasis (PSO) referred to a combined Dermatology-Rheumatology outpatient Clinic (Derm-Rheum) with suspected psoriatic arthritis (PsA) are limited.

Objectives: To assess patient characteristics and treatment changes in PsA patients referred to a Derm-Rheum Clinic.

Methods: Prospective study of PSO patients referred to a combined Derm - Rheum Clinic from February 2018 to June 2020 in a Tertiary University Hospital.

Results: Among 151 patients with PSO referred to the Clinic, 129 (85\%) with a final diagnosis of PsA were included. In $73 \%$ of patients $(n=94)$ PsA was diagnosed there for the $1^{\text {st }}$ time. $56 \%$ were females with a mean age of 55 years and a median disease duration of 14.2 years. At initial evaluation, $95 \%$ had peripheral arthritis, $45 \%$ nail involvement, $23 \%$ axial involvement, $12 \%$ enthesitis and $6 \%$ dactylitis with a median DAPSA score of 20.5 and PASI score of 1.6 , respectively. $31 \%$ of the patients were not receiving any systemic treatment, $45 \%$ were on biologics (30\% as monotherapy, $15 \%$ in combination with non-biologics), $29 \%$ were on non-biologics (14\% as monotherapy, $15 \%$ in combination with biologics or targeted synthetic agents] and $10 \%$ were on targeted synthetic (ts) agents. At last visit (median follow-up: 15 months) only $8 \%$ did not receive any systemic therapy ( $p<0.001$ compared to $1^{\text {st }}$ visit), $62 \%$ were on biologics (39\% monotherapy $-23 \%$ in combination with non-biologics, $p=0.009)$, $46 \%$ were on non-biologics ( $20 \%$ as monotherapy $-26 \%$ in combination with biologics or ts agents, $p=0.01$ ) and $10 \%$ of the patients were on apremilast. The median DAPSA and PASI scores at last visit were 5.3 and 0 , respectively.

Conclusion: About $2 / 3$ of patients with PSO referred to a combined Derm Rheum Clinic with suspicious musculoskeletal complaints were diagnosed for the $1^{\text {st }}$ time as PsA. During follow-up the percentage of PsA patients who started or continued systemic therapy significantly increased with significant improvement of disease activity indices. These data emphasize the value of combined Derm - Rheum Clinics for earlier diagnosis and more efficacious treatment of PsA patients.

Acknowledgements: This work was supported by research grants from the Special Account for Research Grants (S.A.R.G.), National and Kapodistrian University of Athens, Athens, Greece.

Disclosure of Interests: None declared.

DOI: 10.1136/annrheumdis-2021-eular.1640

\section{AB0544 EFFICACY AND SAFETY OF TILDRAKIZUMAB IN PATIENTS WITH AND WITHOUT METABOLIC SYNDROME: 5-YEAR POOLED DATA FROM RESURFACE 1 AND RESURFACE 2}

A. B. Gottlieb ${ }^{1}$, N. Mehta ${ }^{2}$, A. Menter ${ }^{3,4}$, A. M. Mendelsohn ${ }^{5}$, S. Rozzo ${ }^{5}$, M. Lebwohl' ${ }^{1}$ I Icahn School of Medicine at Mount Sinai, Department of Dermatology, New York, United States of America; ${ }^{2}$ National Institutes of Health, National Heart, Lung and Blood Institute, Bethesda, United States of America; ${ }^{3}$ Baylor Scott \& White, Division of Dermatology, Dallas, United States of America; ${ }^{4}$ Texas A\&M College of Medicine, Division of Dermatology, Dallas, United States of America; ${ }^{5}$ Sun Pharmaceutical Industries, Inc., Medical Affairs, Princeton, United States of America

Background: Patients with psoriasis and metabolic syndrome (MetS) may have reduced absolute Psoriasis Area and Severity Index (PASI) response and longterm drug survival. Tildrakizumab is approved for the treatment of moderate to severe plaque psoriasis in the US, EU, Australia, and Japan. Efficacy and safety of tildrakizumab were previously shown to be comparable in patients with vs without MetS after 1 and 3 years of treatment. ${ }^{1}$

Objectives: This post hoc analysis of pooled data from reSURFACE 1 and reSURFACE 2 (NCT01722331/NCT01729754) assessed tildrakizumab efficacy and safety through up to 5 years of treatment in patients with psoriasis with and without MetS.

Methods: reSURFACE 1 and 2 were 3-part, double-blind, randomized controlled phase 3 trials with long-term extensions evaluating tildrakizumab 100 or $200 \mathrm{mg}$ monotherapy at Weeks 0,4 , and every 12 weeks thereafter in adults with moderate to severe plaque psoriasis. ${ }^{2}$ Patients who achieved $\geq 50 \%$ improvement from baseline PASI score (PASI 50 response) at both week 28 and at the end of the phase 3 studies could enter the long-term extension studies continuing the same dose of tildrakizumab. ${ }^{1}$ This post hoc analysis reports results from a pooled data analysis through up to 5 years of tildrakizumab exposure from patients with and without MetS by National Cholesterol Education Program-Adult Treatment Panel III criteria who continuously received the same dose of tildrakizumab throughout the base studies and entered the long-term extensions. Efficacy was assessed as change from baseline PASI score; missing data were handled using multiple 